\title{
EDITORIAL
}

\author{
Hans Irschik • Cristian Marchioli • Michael Krommer • \\ George Weng
}

\section{Changes in the board of editors}

Received: 15 December 2017 / Published online: 15 January 2018

(C) Springer-Verlag GmbH Austria, part of Springer Nature 2018

In connection with his forthcoming retirement from the University of Bayreuth in the year 2019, Professor Nuri Aksel has decided to resign as Editor of Acta Mechanica. Nuri Aksel has served as long-term Editor for the past 17 years, from 2000 to 2017. We, the undersigned Editors of Acta Mechanica, together with our publishing house SpringerNature, would like to express our sincere thanks to Nuri Aksel for his long-lasting efforts. We cordially wish him all the best for successfully finishing several scientific projects in the next time. We are grateful that Nuri Aksel agreed to serve as author of a Reviews and Perspectives Article, which will appear in Acta Mechanica in 2018. At the same time, we are happy to announce that Professor Martin Ostoja-Starzewski of the University of Illinois at Urbana-Champaign has agreed to serve as a new Editor of Acta Mechanica.

His primary responsibility as an Editor will be manuscripts in solid mechanics, with special emphasis on stochastic mechanics.

H. Irschik (ه)

Institute of Technical Mechanics, Johannes Kepler University Linz, Linz, Austria

E-mail: hans.irschik@jku.at

C. Marchioli

Department of Engineering and Architecture, University of Udine, Udine, Italy

M. Krommer

Institute of Mechanics and Mechatronics, Vienna University of Technology, Wien, Austria

G. Weng

Department of Mechanical \& Aerospace Engineering, Rutgers, The State University of New Jersey, Piscataway, NJ, USA 